\title{
Host-parasite Relationships
}

\author{
By G. C. AINSWORTH \\ Department of Botany, University College, Exeter
}

There were taxonomists before there were biochemists and serologists, cytologists and geneticists, and modern taxonomic practice as applied to both macro- and micro-organisms shows abundant evidence of the naturalist's traditional approach. Both before and after the application of diverse special techniques to taxonomy, however, systematists have frequently felt it necessary to employ criteria which would allow them to summate characteristics which could be defined only by workers in other disciplines. Among such criteria the relationship of the parasite to the host takes pride of place for pathogenic micro-organisms and it is to aspects of this relationship that I wish to draw attention. The host-parasite relationship could be discussed comprehensively only on a symposium scale, for in addition to the species concept, the genetics and physiology of both host and parasite are among the many major questions involved and I must, therefore, confine myself to illustrating by examples chosen mainly from the fungi two aspects of the problem: the taxonomic use of what may be termed the spatial relation of the parasite to the host and of the host specialization shown by the parasite.

\section{The spatial relationship}

The spatial relationship of the parasite to the host, that is, the localization of the pathogen to certain organs or tissues, has been used as a criterion for differentiating generic, specific, and intra-specific taxa. Some of the most familiar examples of the use of these, what Ciferri (1952) called 'ecological', characteristics are provided by the Fungi Imperfecti among which the genera Phoma and Phyllosticta are differentiated by the occurrence of the former on the stems and the latter on the leaves of the host plants. A similar, if not quite so clear-cut distinction is made between the allied pair of genera Diplodina (usually on stems, rarely on leaves) and Aschochyta (usually on leaves, less frequently on stems) in which the spores, produced as in Phoma and Phyllosticta in small flask-shaped structures (pycnidia) immersed in the host tissue, are 2-celled instead of 1-celled as in the first pair of genera. Another example at the generic level is provided by the Dermatophytes in which Epidermophyton is distinguished from Microsporum and Trichophyton by the inability to attack hair. On the other hand, the localized sporulation shown by the hair-invading ringworm fungi on the surface of (in the 'ectothrix' type), or inside (the 'endothrix' type), the infected hair has also been advocated as a generic or infrageneric criterion. The smut fungi (Ustilaginales), an ubiquitous order of plant pathogens, provide instances of the differentiation of species and varieties by 
similar criteria. For example, Ustilago lygei was differentiated from the morphologically similar stem smut of grasses, $U$. hypodytes, by reason of attacking the inflorescence and not the culm while the same differential character was used to distinguish $U$. tritici var. foliicola as a leaf-invading variety of the loose smut of wheat ( $U$. tritici) which is normally confined to the inflorescence.

\section{The physiologic relationship}

Although host specialization has been much more extensively employed as a taxonomic criterion than has localization of the parasite on the host it has rarely been used at a generic or supra-generic level. Among the better known examples, the separation by Bergey et al. of plant pathogenic bacteria from similar coliform organisms as the tribe Erwiniae comprising the genera Erwinia (flagella peritrichous) and Phytomonas (flagella polar or absent) may be recalled. For specific and infra-specific taxa host specialization (or alleged specialization) has been exceedingly popular as any check-list of plant pathogenic fungi suggests. Up to $\mathbf{5 0} \%$ or more of the specific epithets are found to be derived from host names.

The reality of biological races is indisputable and their existence has for long tried the patience and exercised the ingenuity of both taxonomists and plant pathologists. It was among the rust fungi (Uredinales), a group of obligate plant parasites, that biological races were first recognized about 60 years ago, and since then the smuts and many other groups of fungi have been shown to exhibit the same phenomenon. Among the smuts, morphologically similar forms cause similar diseases in wheat and barley but the fungus from wheat will not infect barley and vice versa. This host specificity led to the erection of the two species, Ustilago tritici, the cause of loose smut of wheat, and $U$. nuda, the cause of loose smut of barley. Sometimes small biometrical differences can be detected between such forms, but usually any morphological differences are too slight to have any practical taxonomic value and the taxonomic treatment is frequently modelled on that of the black stem rust, Puccinia graminis. This rust exhibits a series of races specialized for the parasitism of a range of cereals and grasses and it has been customary to treat these races as 'formae speciales' designated by Latin epithets (e.g. Puccinia graminis f.sp. tritici) to give names which have been used by many cereal pathologists and others as trinomials (e.g. P. graminis tritici). By using a series of carefully selected pure bred varieties of the host it is possible to demonstrate within one forma specialis the existence of large numbers of subraces (some $\mathbf{3 0 0}$ for $\boldsymbol{P}$. graminis tritici) for the nomenclatural treatment of which the International Code of Botanical Nomenclature provides no guidance. A knowledge of such races and exchange of information on their geographical distribution is of great practical importance to plant pathologists who, therefore, agreed among themselves on an unofficial registration of these races at Prof. Stakman's laboratory at the University of Minnesota which acts as an international clearing house and allocates numbers by which the different races are distinguished. 
There is a further complication. Many rusts are heteroecious. Their life cycles involve pairs of distinct, and frequently taxonomically widely unrelated, hosts. On one host a haploid mycelium undergoes fusion with an element of another haploid mycelium and as a result binucleate aecidiospores are produced. These aecidiospores bring about infection of the alternate host in which a binucleate (dikaryotic) mycelium produces a second type of dikaryotic spore (the uredospore) and finally a third type of spore (the teleutospore) which is diploid. The different formae speciales of Puccinia graminis have a common aecidial (gametophytic) host in barberry (Berberis). For other morphologically similar races, those of the brown rusts of cereals, for example, several different aecidial hosts belonging to several different families are involved. In such cases it is common practice among uredinologists to accord specific rank to the biological races. The result is a number of morphologically indistinguishable rusts differing in both aecidial and uredospore-teleutospore hosts and much confusion. (For further details the useful review by Dennis, 1952, may be consulted.)

\section{Taxonomic effects}

These few examples must suffice as a background for a brief consideration of some of the effects of the use of criteria derived from host-parasite relationships on taxonomic practice.

The spatial relationship is usually employed for reasons of convenience. As Dennis (1946) has pointed out, the traditional allocation of pycnidial fungi to the form genera Phoma and Phyllosticta according to whether they are collected on stems or leaves has long been recognized as irrational; and its retention is a tribute merely to its convenience and a confession of the necessity of grouping for easy reference the innumerable names that have been applied in the literature to these fungi. The spatial relationship may, however, at times be a constant and reliable feature as is the specificity of Epidermophyton floccosum for skin. Such characters are therefore eligible for consideration as taxonomic criteria, but there is a growing weight of opinion among mycologists that it is always best to define the basic taxonomic categories by mycological criteria and during recent years the genus Epidermophyton has been acceptably redefined in mycological terms. For the same reason, the names $U$ stilago lyge $i$ and $U$. tritici var. foliicola have been reduced to synonyms of $U$. hypodytes and $U$. tritici, respectively.

The widespread use of host specialization for differentiating species has presented mycologists with a major dilemma, for in certain groups the easiest way, and sometimes the only way, to identify a fungus is not by a study of the fungus but by identifying the host plant. The use of this method has also been one factor leading to a great multiplication in the number of species. For all Ascomycetes the number of generally accepted species per genus is $\mathbf{8 . 3}$ and for 11 of the 14 orders this number varies from $2 \cdot 3$ to $10 \cdot 5$. In the remaining 3 orders, the Laboulbeniales, Erysiphales (powdery mildews), and Taphrinales, all orders in which host specificity has played an important part in speciation, 
the number of species per genus are $12 \cdot 5,16 \cdot 7$ and $20 \cdot 8$, respectively. For rusts (Uredinales) the number is 36 .

There is however a third and perhaps even more important aspect of the impact of the host on speciation. The average mycologist is impressed by the apparently greater frequency among fungi pathogenic for man and animals of fungi which are normally saprophytes. This impression is probably distorted because although several major groups of fungi are composed of obligate parasites of plants the emphasis on host specialization for differentiating species has certainly multiplied plant pathogens at the expense of nonpathogens. For example, most species of Phoma that have been described are parasites, but the relation of these forms to one another and to the forms found in the soil and as air-borne spores is obscure. It is almost certain that many of the plant pathogenic species of this genus, reduced to physiologic races and united specifically, could be amalgamated with related saprophytes. The same applies to such a genus as Fusarium and it is possible, now that dermatophytes and dermatophyte-like fungi have been recorded from the soil, that under a more natural and rational classification certain ringworm fungi will eventually find a place in the same genera, or even species, as nonpathogenic counterparts.

There is, as already mentioned, a modern tendency to favour the description of genera and species of fungi in mycological terms and whenever possible morphology is given precedence over other considerations. A good example of the application of this principle is provided by G. W. Fischer's Manual of the North American Smut Fungi, 1954. In this work morphologically similar smuts, such as Ustilago tritici and $U$. nuda, are amalgamated with commendable consistence when related hosts are involved, but the author was unwilling to break with tradition and to unite morphologically similar smuts specialized for hosts belonging to different families. Much work remains to be done before the specialist can be satisfied by an appropriate intra-specific taxonomy and nomenclature for many groups, but there is no reason to suppose that the problem is insoluble. The host-parasite relationship certainly has taxonomic value but for the differentiation of species of fungi I feel that the interests of mycology would be best served by responding to the appeal made a few weeks ago by Synder \& Hansen (1954) that fungi should be classified at the species level 'for what they are, not for what they do or where they occur'.

\section{REFERENCES}

Ciferri, R. (1952). The criteria for definition of species in mycology. Ann. mycol., Berl. 30, 122.

Dennis. R. W. G. (1946). Notes on some British fungi ascribed to Phoma and related genera. Trans. Brit. mycol. Soc. 29, 11.

Dennis, R. W. G. (1952). Biological races and their taxonomic treatment by mycologists. Proc. Linn. Soc., Lond. 163, 47.

SNyder, \& Hansen. H. N. (1954). Concepts of species and nomenclature evolved from studies in the fungus genus Fusarium. Rapp. viii, Int. bot. Congr., Sect. 18-20, 171. 